\title{
The influence of water-conservation messages on reducing household water use
}

\author{
Isaac B. Addo ${ }^{1}$ (D) Martin C. Thoms ${ }^{1} \cdot$ Melissa Parsons $^{1}$
}

Received: 15 August 2018 / Accepted: 13 June 2019 / Published online: 21 June 2019

(c) The Author(s) 2019

\begin{abstract}
As water crises become severe, the desire to explore alternative strategies that focus on the demand-side of water-conservation increase. Changing behaviour through persuasion (message framing) can be an integral part of providing water demand solutions. In this study, we examined the effectiveness of messages related to household water use on water scarcity and intentions to act. We tested whether relationships between communication and water conservation were mediated via increasing capability, opportunity, and motivation behaviour (COM-B dimensions). We applied two message types related to concern about severe water scarcity and conservation strategies to the behaviour change conditions in two combinations: (1) severe water scarcity and water-saving tips/strategies, and (2) severe water scarcity and no water-saving tips/strategies. There was broad support for the hypothesis that COM-B dimensions would mediate the effect of message type on water scarcity concern and intentions to act in conservation activities. Households that received the message framed in terms of water-saving tips/ strategies expressed greater water scarcity concern and higher intention to act than those that received the no water-saving tips/strategies message. Mediation analyses showed that the message framed in terms of specific water-saving tips/strategies was mediated by increasing households' capacity (self-efficacy), opportunity and/or motivation in water-conservation actions. Thus, specific water-conservation strategies made available to households have a stronger impact on water-conservation behaviour because these messages appeal to behavioural change conditions.
\end{abstract}

Keywords Water-conservation behaviour $\cdot$ Water use $\cdot$ Communication $\cdot$ Behaviour change strategies $\cdot$ Intentions to conserve

\section{Introduction}

Water security is important in highly variable, unpredictable water environments where demand for this resource is increasing. Water security is one of the 31 leading interconnected overall risks to competitiveness (World Economic Forum 2014). Factors contributing to the risk of water security for households include population growth, industrial growth, and the unpredictability of water supply. Climate change also exacerbates water crises globally, reducing river flows and dam storage volumes (Postel et al. 1996; Wilbanks and Kates 2010). The possible consequences of water scarcity include acute water deficits, reduced food security, degradation of riparian ecosystems, extinction of species,

Isaac B. Addo

iaddo@myune.edu.au

1 Riverine Landscapes Research Laboratory, University of New England, Armidale, NSW 2351, Australia difficulties in maintaining a variety of sources of water supply as well as increased societal stress (Postel et al. 1996). In addition, water crises threaten efforts to reduce the carbon footprint and maintain the affordability and constancy of municipal water supply and treatment systems (Hoekstra and Chapagain 2007; Richter 2014).

A greater frequency in water crises increases the importance of strategies that address water demand (demand-side) in water management and planning (Gober et al. 2010; Fielding et al. 2012). Demand-side strategies are measures or initiatives that result in a reduction in the expected water use or the demand for water by resource providers (e.g. a utility) as part of an overall corporate-planning and capital-investment process (Stiles 1996). Most demand-side strategies adopted by water utilities focus on water use efficiency, water supply restrictions, and regulations with consequences as a means of controlling water use (Bemelmans-Videc et al. 2011; Farley and Bremer 2017). Demand-side strategies dominate water-conservation approaches (McGranahan 2002)

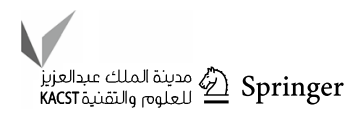


but are restrictive because they do not encourage voluntary individual behavioural change. These strategies are essentially a command-and-control approach to household water usage. More effective water-conservation outcomes may be achieved through persuasion (message framing that influences the causal mechanisms of behaviour) for behavioural and attitudinal change among water consumers.

Individual conservation behaviours can be influenced by a variety of factors such as persuasion (framing effective conservation messages that build on behavioural change mechanisms), knowledge, communication campaigns and fostering attitudes supportive of a desired action (McKenzie-Mohr et al. 1995; Fielding and Roiko 2014). Water-conservation outcomes may be improved through persuasion (message framing) for behavioural and attitudinal change among water consumers. The communication of conservation messages encourages behavioural changes that result in sustainable water conservation. Communication includes the framing and content of messages for household water-conservation behaviour. Households may receive information about water scarcity and specific water-saving strategies (e.g. use of dual-flush toilets) to conserve water (Seyranian et al. 2015). Such information can transform behaviours impacting water quality and supply (Jorgensen et al. 2009) and challenges the belief that wasting water is acceptable. However, research emphasising communication about resources has not included the wider psychological-social dimensions for developing and testing theories of attitudinal change and conviction (Russell and Green 2009; Maas et al. 2017; Landon et al. 2016). Research addressing behaviour change such as cigarette smoking, substance use among adolescents and energy and water conservation has shown knowledge (knowledge-deficit model approach) to be a strong correlate (Bryan et al. 2000; Fisher et al. 1994; Fisher and Fisher 1996). For example, a well-designed education campaign can change beliefs and increase knowledge but this change in knowledge is associated with only a small, short-term change in behaviour (Schultz 2002).

Agencies implementing strategies and interventions have achieved behavioural outcomes. Research indicates that procedural knowledge predicts sustainable behaviour such as recycling behaviour (Schultz 2002). For example, how knowledgeable a person is about which measures are applicable, when and where information is needed, the more likely that individual is to change behaviour. However, Schultz (1999) claimed that distributing information materials can increase knowledge but this change in knowledge is associated with short-lived change in behaviour. Sustainability-related water-conservation interventions such as retrofitting programs, water restrictions, and information campaigns have many success stories worth mentioning such as reduction in water use (Fielding et al. 2013), but challenges and barriers remain for achieving long-term behaviour change
(McKenzie-Mohr 2008). Information campaigns often are ineffective because the motives behind behaviour changecausal mechanisms of behaviour are ignored (Schultz 2002). Despite the reductions in demand that have been achieved through water-utility strategies, these are restrictive because they are framed as a command-and-control approach and do not encourage voluntary behavioural change to water use. To have sustained water conservation, greater emphasis should be placed on changing behaviour. Thus, disseminating information and/or communicating conservation messages should tailor with the causal mechanisms of behaviour that result in changes to an individual's attitudes, desires, and motivations as an alternative approach to conserving water. The psychological-social factors of capability, opportunity, and motivation are the mechanisms of changing behaviour. These psychological-social mechanisms impacting behaviours when targeted and connected to conservation messages and cultural influences can bring about sustainability (e.g. framing of messages connected to the behaviour mechanisms-COM-B system).

To achieve greater success in water-conservation behaviour, messaging may be improved by understanding the psychological-social mechanisms of behaviour change. The Behaviour Change Wheel (BCW) model (Michie et al. 2011), based on behaviour change theory, contains three distinct behaviour conditions: capability, opportunity and motivation (COM-B dimensions) which can influence conservation messages presented to a receptive audience (Michie et al. 2011; Hine et al. 2013). Capability is defined as acquiring psychological and physical ability/self-efficacy to adopt specific behaviours or actions, including having suitable insight, knowledge and skills (Michie et al. 2011). Opportunity explains external factors to the individual that make the behaviour conceivable or prompt it, such as a social surrounding or physical environment that permits or prohibits a behaviour. Motivation describes the cognitive processes that vitalise and guide behaviour, such as habitual responses, emotional responses, and rational decision-making. These cognitive processes involve reflective motivation, such as making-good intentions or doing appraisals, and automatic motivation, involving emotional and impulse responses. Proenvironmental behaviour can be sustained when intervention activity (e.g. conservation messages) targets one or more conditions within this behaviour system (Michie et al. 2011).

The BCW framework and COM-B system have been applied in several disciplines and contexts (e.g. Addo et al. 2018; Alexander et al. 2014; Barker et al. 2016; Jackson et al. 2014; McLeod et al. 2015). Addo et al. (2018) found that the psychological-social factors of capability, opportunity, and motivation are the mechanisms of changing behaviour in water conservation. The authors contended that these mechanisms determine specific intervention strategies to target more effective measures and solutions that 
promote sustainable water-conservation behaviour. Moore et al. (2014) used the BCW framework with health-related behaviours to develop a guide that links identified barriers and intervention activities to behaviour change theory. The study concluded that the approach allows policy-makers and implementers to identify potential strategies to overcome barriers to health-related behaviours. Barker et al. (2016) used the BCW framework in developing an intervention which aims to promote regular, long-term use of hearing aids by adults with acquired hearing loss. The study found that behavioural planning might be more likely to occur if audiologists' psychological capability, physical and social opportunity, and reflective and automatic motivation were addressed. Despite the potential for the BCW framework to assist in promoting sustainable behavioural change, it is yet to be applied to the area of information approach to water conservation. The aim of this study is to examine whether COM-B conditions mediate the effect of the type of waterconservation message on water scarcity concern and households' intentions to engage in water-conservation behaviour.

\section{Methods}

\section{Recruitment of study participants}

Study participants were recruited through a social research panel (Qualtrics ${ }^{\mathrm{TM}}$ ) in March and April 2017 and asked to undertake an online survey. Social research panel/custom online panel (i.e., online research panel or internet panel) is a group of pre-screened respondents who have expressed a willingness to participate in surveys and/or customer feedback sessions. It is also known as a customer advisory panel or proprietary panel and is a standard approach in psychological and social sciences research. This approach helps researchers to get sample responses for their surveys and the direct contact of participants is unknown to the researchers. Participants received a reward commensurate with the time commitment involved in completing the survey. Participants had to be at least 18 years of age, have responsibility for paying utility bills (including bills for their household's water use), have access to a garden as part of their property, and reside in New South Wales (NSW), Australia. The research was approved by the University of New England Human Research Ethics Committee.

\section{Characteristics of study participants}

The sample comprised of 510 NSW residents. Participants were aged from 18 to 84 years (Mean age $=56.08$, $\mathrm{SD}=14.71)$, with equal numbers of males and females. Most participants (35\%) had completed technical/vocational/ TAFE education, $28 \%$ had completed year 12 at high school,
$19 \%$ had achieved a bachelor's degree and $18 \%$ completed a higher degree. Sixty-eight per cent described their residential situations as either solely or jointly owned property, $28 \%$ reported residence in a rented property, and $4 \%$ indicated that they resided in a property owned or rented by family or friends. In terms of access to a garden as part of their property, $91 \%$ declared access to a garden. Regarding responsibility for paying utility bills, $60 \%$ of the sample was solely responsible, and $40 \%$ shared the responsibility with other household members. Respondents were not screened by the type of water supply (i.e., reticulated water supply and non-reticulated water supply) and location.

\section{Experimental procedure}

Following questions on demographic data, we assessed the effect of water-conservation messages on water scarcity concern and intentions to act in conservation activities. Participants completed a questionnaire assessing the extent to which receiving the water-conservation message types could influence their water scarcity concern and intentions to act in conserving water. Videos containing the water-conservation message types were then shown to participants. We then assessed the effect of water-conservation message videos using the COM-B dimensions as mediating variables on water scarcity concern and intentions to act in conserving water.

\section{Measures evaluating the effects of messages on water scarcity concern and intentions to act}

Water scarcity concern was assessed using 15 items appraising the degree to which participants understood the need for water-conservation message and the degree to which it inspired them to adopt conservation measures by installing water-saving devices (Appendix 1). For example, participants indicated whether they had installed waterefficient devices (e.g. "I have installed a dual-flush toilet in my house") by selecting 1 (no) or 2 (yes). The internal consistency of the water scarcity concern scale was good (Cronbach's $\alpha=0.78$ ). Intention to act was assessed using 23 items (Appendix 1) that gauged participants' opinions about how the framing and content of the water-conservation message videos when watched could alter their behaviour and put water-conservation measures into action (e.g. "I allow my lawn to go brown if there is insufficient rain", "I use drought-resistant grass") by selecting 1 (no) or 2 (yes). The internal consistency of the intentions to act scale was high (Cronbach's $\alpha=0.89$ ). 


\section{Analysis}

A Chi-square test was conducted in the statistical package SPSS version 24 to determine whether the message types have an effect on water scarcity concern and intentions to act. Water-conservation message types were coded as 1 for "water-saving tips/strategies" and 2 for "no water-saving tips/strategies". Water scarcity concern and intentions to act scales were regressed against conservation message types. The effects of messages on water scarcity concern and intentions to act scales were assessed by using the "yes" or "no" responses which show the effects of message types on water scarcity concern and intentions to act.

\section{Allocation of water-conservation message videos}

Participants were randomly assigned to view one of two household water-conservation messages, differing in their treatment of conservation strategies and information about options for conserving water: (1) severe water scarcity with water-saving tips/strategies; and, (2) severe water scarcity with no water-saving tips/strategies. Participants in the water-saving tips/strategies group viewed a video selected from YouTube (https://www.youtube.com/watch?v=4MDLp VHY 8LE\&t=6s). This message outlined the negative impacts of water crises on the environment and highlighted water crisis and water shortage as a serious global concern needing to be addressed. The water-saving tips/strategies message also described water-conservation strategies that households could adopt. These strategies were described as providing holistic approaches to secure water supply and ensuring environmental benefits by reducing the quantity of water wasted by households. It likewise encouraged and required active involvement in and commitment to conservation actions, providing step-by-step water-conservation measures. Participants in the no water-saving tips/strategies group also viewed a video selected from YouTube (https://www.youtube.com/watch? $\mathrm{v}=\mathrm{fLMn} 2 \mathrm{P} 5 \mathrm{q} 1 \mathrm{ho}$ ). The no water-saving tips/strategies message outlined the same negative impacts of water crises on the environment but did not describe water-conservation strategies that households could adopt. Thus, the only distinction between the watersaving tips and no water-saving tips conservation messages was the inclusion of strategies that households could adopt to conserve water.

Immediately after viewing the water-conservation message videos, participants in both groups answered questions evaluating the degree to which the water-conservation message type influenced their water scarcity concern and intentions to act in reducing water consumption. Participants' responses to the water-conservation messages were assessed using 39 items using COM-B dimensions (capability, opportunity and motivation behaviour) as a taxonomy to evaluate water scarcity concern and intentions to act (Appendix 2).

The capability dimension was measured by 17 items, comprising two psycho-social dimensions of physical capability and psychological capability, which measure a participant's capacity to engage in water-conservation practices. Physical capability was assessed with eight items describing physical skills, strength or stamina in conserving water (Appendix 2). Participants indicated their levels of engagement with each statement using a Likert scale ranging from 1 (never) to 5 (always). The physical capability scale had high internal consistency (Cronbach's $\alpha=0.86$ ). Psychological capability was assessed using nine items (Appendix 2). These items determine the extent to which participants' relevant knowledge, reasoning and psychological skills related to the perception that the household water use communications were relevant and worthwhile. The capability dimensions also encouraged household members to engage in water-conservation activities and seek more information about water-conservation practices. The Likert scale ranged from 1 (strongly disagree) to 5 (strongly agree) and the psychological capability scale also had high internal consistency (Cronbach's $\alpha=0.95$ ).

The opportunity dimension was measured with five items addressing a range of physical and social water-conservation conditions in the external environment that activate or inhibit water-conservation behaviour. Physical opportunity was assessed using three items (Appendix 2), indicating factors external to participants which activate or inhibit a water-conservation behaviour. The Likert scale ranged from 1 (strongly oppose) to 5 (strongly support). The physical capability scale had high-quality internal consistency (Cronbach's $\alpha=0.89$ ). Social opportunity was measured with two items (Appendix 2), indicating social cues or community values and norms that persuade or inhibit water-conservation behaviour. The Likert scale ranged from 1 (strongly disagree) to 5 (strongly agree) and the internal consistency for the social opportunity scale was high (Cronbach's $\alpha=0.95$ ).

The motivation dimension was assessed using 17 items measuring reflective and automatic mechanisms that activate or inhibit water-conservation behaviour. Reflective motivation was assessed by 10 items (Appendix 2), evaluating the extent to which respondents' objectives and evaluations perceived the household water use messages to be convincing about water-conservation actions. The Likert scale ranged from 1 (does not describe me) to 5 (describes me extremely well). The reflective motivation scale displayed high internal consistency (Cronbach's $\alpha=0.84$ ). Automatic motivation was assessed with seven items (Appendix 2), weighing the extent to which respondents' emotional reactions, desires (wants/needs), inhibitions, and reflex responses perceived the household water use messages to be credible about 
water-conservation practices. The Likert scale ranged from 1 (does not describe me) to 5 (describes me extremely well). The automatic motivation scale had high internal consistency (Cronbach's $\alpha=0.93$ ).

\section{Analysis}

Data were subjected to two types of analyses. First, a Principal Components Analysis (PCA) was undertaken on a sub-set of the 39 psychological-social constructs of water conservation to make sure that the constructs loaded to the three hypothesised variables of COM-B dimensions based on causal effect mechanism relationship. This refined the item set prior to undertaking the pathway analysis. We used the direct Oblimin approach to rotate the dataset with delta $(\Delta)$ fixed to 0 to allow moderate correlations among the components. This relaxed the orthogonality constraint and gained simplicity in the interpretation (Thurstone 1947).

Second, path analysis (Arbuckle 2006) was conducted to test the strength of behaviour conditions (COM-B dimensions) in mediating the effects of the water-conservation message types on water scarcity concern and households' intentions to engage in conservation behaviour. The performance of the model was assessed using relative Chi-square (CMIN/DF), goodness-of-fit index (GFI), comparative fit index (CFI), root-mean-square error of approximation (RMSEA) and the standardised root-mean-square residual (SRMR). To assess good model fit, data must fit: $\chi^{2} / d f<3.0$, GFI $>0.90$, CFI $>0.90$, RMSEA $<0.05$ (90\% CIs [0.05, $0.10]$ ), and SRMR $<0.08$. The pathway analysis was conducted with maximum likelihood estimation (MLE). Bootstrapping was used for calculating the significance of the indirect pathways to generate confidence intervals.

\section{Results}

The PCA analysis showed no outliers among the variables and communalities were close to 0.40 , showing that all items contributed a substantial amount of shared variance to the solution. Scree test showed an unambiguous threecomponent solution that explained a total of $65.08 \%$ of the variance in the data displaying moderate simple structure with matrix loadings ranging from 0.37 to 0.87 . The 39 psychological-social loading items which exceeded 0.50 were obtained for further analysis (Table 1). Two of the 39 psychological-social items tolerated high crossing-weight (e.g. $>0.30$ ), six items did not load above the recommended threshold of 0.50 . These eight items were excluded from further investigations. For each component loading, mean item scores were used in the pathway analyses. In the rotated factors, as shown in Table 1, capability, opportunity, and motivation all had high positive loadings. The first two components assessed capability and opportunity dimensions and the third component assessed the motivation dimension for conserving water. These underlying factors were statistically significant in predicting household water-conservation behaviour. The three principal components explained more than $65 \%$ of the total variance. This suggests that considering the COM-B dimensions linear combinations of the original variables should be enough to explain most of the variance in the data sampled from the model. Matrix loadings above 0.40 are reported, following the recommendations of Field (2000). For each component loading, mean item scores were used in subsequent analyses. The COM-B dimensions and other study variables of household waterconservation behaviour were all significantly and positively correlated (Table 2).

There was a significant effect of the two messages on intentions to act $\chi^{2}(1, N=510), 88.46, p<0.001$ and water scarcity concern $\chi^{2}(1, N=510), 8.51, p<0.001$. The influence of message types on water scarcity concern and intentions to act were $75 \%$ for participants who perceived that water-saving tips/strategies could impact conservation actions and $25 \%$ for participants who perceived that no water-saving tips/strategies message type responses could influence water-conservation actions (Fig. 1).

The model presented a significant fit to the data: $\chi^{2}$ $(4, N=510)=6.80, p=0.15 ; \chi^{2} / d f=1.70, \mathrm{GFI}=0.94$, $\mathrm{CFI}=1.00 ;$ RMSEA $=0.04$, 90\% CIs $[0.00,0.09]$, $\mathrm{SRMR}=0.02$. All testing of indirect effects was calculated through decomposition tests grounded upon 1000 bias-corrected bootstrapped samples in AMOS. Given the acceptable model fit, the pathway coefficients between water-conservation messages and water scarcity concern and intentions to act were significant in the hypothesised directions. There was a significant effect of message type on water scarcity concern (Fig. 2). For the interaction involving message types and the COM-B dimensions, providing information about water-saving strategies produced significant increases in water scarcity concern.

Message type was mediated by participants' views about capability and motivation behaviour. The significant path coefficients showed that capability appeared to be particularly important in mediating the impact of the water-conservation message type on water scarcity concern $(0.42$, $p<0.01$ ) (Fig. 2). Participants who scored higher capability reported greater levels of psychological perception of water scarcity concern. Motivation elicited a lower but significantly positive score $(0.24, p<0.01)$. A lower score on motivation predicted lower levels of water scarcity concern. Opportunity had a significant moderate positive effect $(0.15$, $p<0.01)$ on water scarcity concern, however, it mediated both message types. As expected, participants in the watersaving tips/strategies message condition, relative to those in the no water-tips/strategies message condition expressed

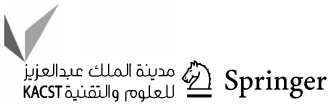


Table 1 Factor loadings of psychological-social constructs of water conservation into the COM-B dimensions

\begin{tabular}{|c|c|c|c|c|}
\hline Dimension & Items & $\begin{array}{l}\text { Compo- } \\
\text { nent } 1 \\
\text { Capability }\end{array}$ & $\begin{array}{l}\text { Component } \\
2 \\
\text { Opportunity }\end{array}$ & $\begin{array}{l}\text { Compo- } \\
\text { nent } 3 \\
\text { Motivation }\end{array}$ \\
\hline \multirow{10}{*}{ Psychological capability } & & & & \\
\hline & Looking out for news and facts on water shortages and crises areas & 0.85 & & \\
\hline & Knowing the effective methods of watering garden to save water & 0.84 & & \\
\hline & $\begin{array}{l}\text { Understanding the negative impacts of water scarcity on sustainable liveli- } \\
\text { hood }\end{array}$ & 0.79 & & \\
\hline & Providing information about water conservation to householders & 0.79 & & \\
\hline & $\begin{array}{l}\text { Taking feedback about the level of water consumption seriously to check } \\
\text { my water usage }\end{array}$ & 0.76 & & \\
\hline & Prioritising ecological issues such as water scarcity and pollution & 0.78 & & \\
\hline & Understanding the impacts of water shortages and conservation processes & 0.71 & & \\
\hline & Communicating the severity of water scarcity to neighbours/families & 0.66 & & \\
\hline & Learning about water crises and their consequences on the environment & 0.71 & & \\
\hline \multirow[t]{8}{*}{ Physical capability } & Harvesting rainwater for the garden & 0.44 & & \\
\hline & Using a bucket instead of a hose to water the garden & 0.52 & & \\
\hline & Using water-efficient appliances in my house & $\mathbf{0 . 5 3}$ & & \\
\hline & Checking and fixing leaking water-efficient plumbing fixtures & 0.55 & & \\
\hline & Planting hardy plants/drought-resistant xeriscape gardening & 0.48 & & \\
\hline & Having power spray attached to a hose & 0.57 & & \\
\hline & Owning water-efficient electrical appliances & & & \\
\hline & Minimising the flushing of toilets and bath times & 0.40 & & 0.49 \\
\hline \multirow[t]{2}{*}{ Social opportunity } & People conserve water because of their cultural beliefs & & 0.86 & \\
\hline & Social pressure is a key factor for water conservation & & 0.81 & \\
\hline \multirow[t]{3}{*}{ Physical opportunity } & $\begin{array}{l}\text { I think financial incentives or rebates are likely to promote water-conserva- } \\
\text { tion measures }\end{array}$ & & 0.37 & \\
\hline & I strictly adhere to water restrictions & 0.47 & 0.46 & \\
\hline & It is advisable to use quality water-efficient appliances & & 0.41 & 0.39 \\
\hline \multirow[t]{10}{*}{ Reflective motivation } & Informing myself about flow regulators & & & 0.72 \\
\hline & Supporting environmental pressure groups to protect the natural resources & & & 0.49 \\
\hline & Informing myself about certified water-efficient appliances & & & 0.63 \\
\hline & $\begin{array}{l}\text { Feeling upset when I see someone using water to wash the footpath/side- } \\
\text { walk or driveway }\end{array}$ & & & 0.63 \\
\hline & $\begin{array}{l}\text { Feeling indignant at the lack of awareness of some people regarding water } \\
\text { conservation }\end{array}$ & & & $\mathbf{0 . 5 3}$ \\
\hline & $\begin{array}{l}\text { Feeling frustrated when I see a toilet/tap running without anyone doing } \\
\text { anything about it }\end{array}$ & & & 0.86 \\
\hline & Feeling guilty when I leave a tap running & & & 0.79 \\
\hline & Feeling good when I can save water & & & 0.72 \\
\hline & Feeling happy to see someone who is trying to save water & & & 0.69 \\
\hline & Feeling upset by the waste of water in public places & & & 0.71 \\
\hline \multirow[t]{7}{*}{ Automatic motivation } & Rinsing vegetables under running water & & & 0.82 \\
\hline & Showering for less than $3 \mathrm{~min}$ & & & 0.51 \\
\hline & Wanting to complain when I see someone wasting water & & & 0.56 \\
\hline & Washing vegetables in a bucket or sink instead of running water & & & 0.59 \\
\hline & Stopping what I am doing to turn off a dripping tap & & & 0.76 \\
\hline & Conserving water is my responsibility & & & 0.68 \\
\hline & Checking for regular plumbing leaks & & & 0.57 \\
\hline
\end{tabular}

Extraction method: Principal component analysis. Rotation method: Oblimin with Kaiser Normalization. Eigenvalue $>1$. Loadings in bold indicate those items retained in the final psychological-social dimension scales. Loading thresholds below 0.30 are not included in the table. Following the recommendations of Field (2009), pattern matrix loadings are reported. These values are partial correlations between the scale items and components, after controlling for the variance shared by other retained components. Bold value indicates item scores (loadings above the recommended threshold 0.50) for each component used in the path analyses 
Table 2 Zero-order correlations and descriptive statistics for all study variables $(N=510)$
Fig. 1 Effects of a water-saving tips/strategies and b no watersaving tips/strategies message types on water scarcity concern and intentions to act. Yes and No indicate whether message types influence water scarcity concern and intentions to act

\begin{tabular}{lllllllll}
\hline Variable & 1 & 2 & 3 & 4 & 5 & 6 & 7 & 8 \\
\hline
\end{tabular}

1. Sex

2. Age

3. Message Frame

$-0.25 * * *$

4. Capability

5. Opportunity

$0.12 *$

$0.12 *$

$0.18 * * \quad 0.01$

$0.61 * * *$

$0.06-0.01$

$0.48 *$

$0.59 * * *$

6. Motivation

$0.18^{* * *}$

$-0.19^{* * *}$

$0.25 * * *$

$0.26 * * *$

$0.32 * *$

7. Water Scarcity Concern

0.04

8. Intentions to Act

$0.23 * * *$

0.08

$0.10^{*}$

$0.12 * \quad 0.07$

0.04

2.29

$0.44 * * *$

$0.27 * * *$

$0.21 * * \quad 0.01$

$M$ (total sample)

0.76

0.50

4.12

3.80

3.35

$0.24 * *$

SD (total sample)

0.61

0.54

$\begin{array}{llll}0.41 & 0.34 & 0.80\end{array}$

Sex was coded: $1=$ male, 2 =female, $3=$ other. Message type was coded: $1=$ severe water scarcity-inadequate conservation strategies, $2=$ severe water scarcity-adequate conservation strategies

$* p<0.05 ; * * p<0.01 ; * * * p<0.001$ (a) Water-saving tips/strategies

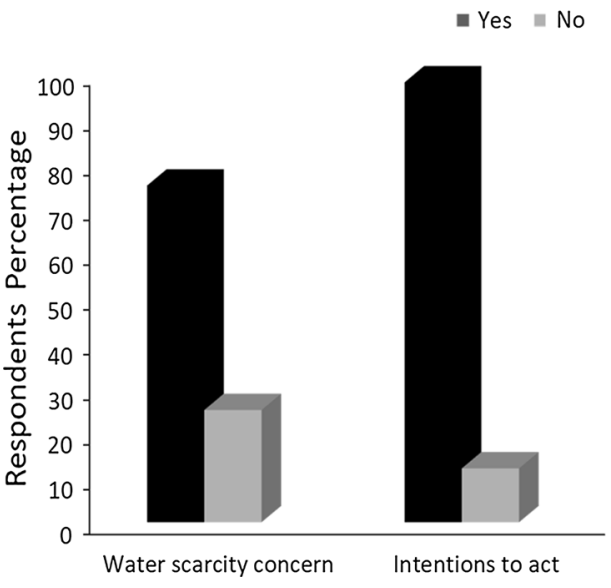

(b) No water-saving tips/strategies

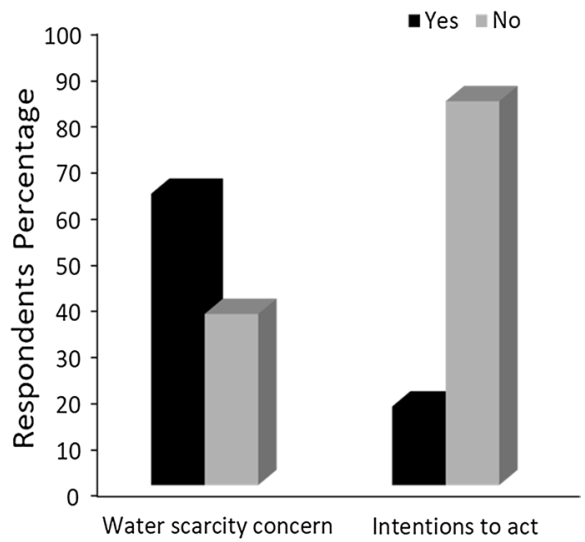

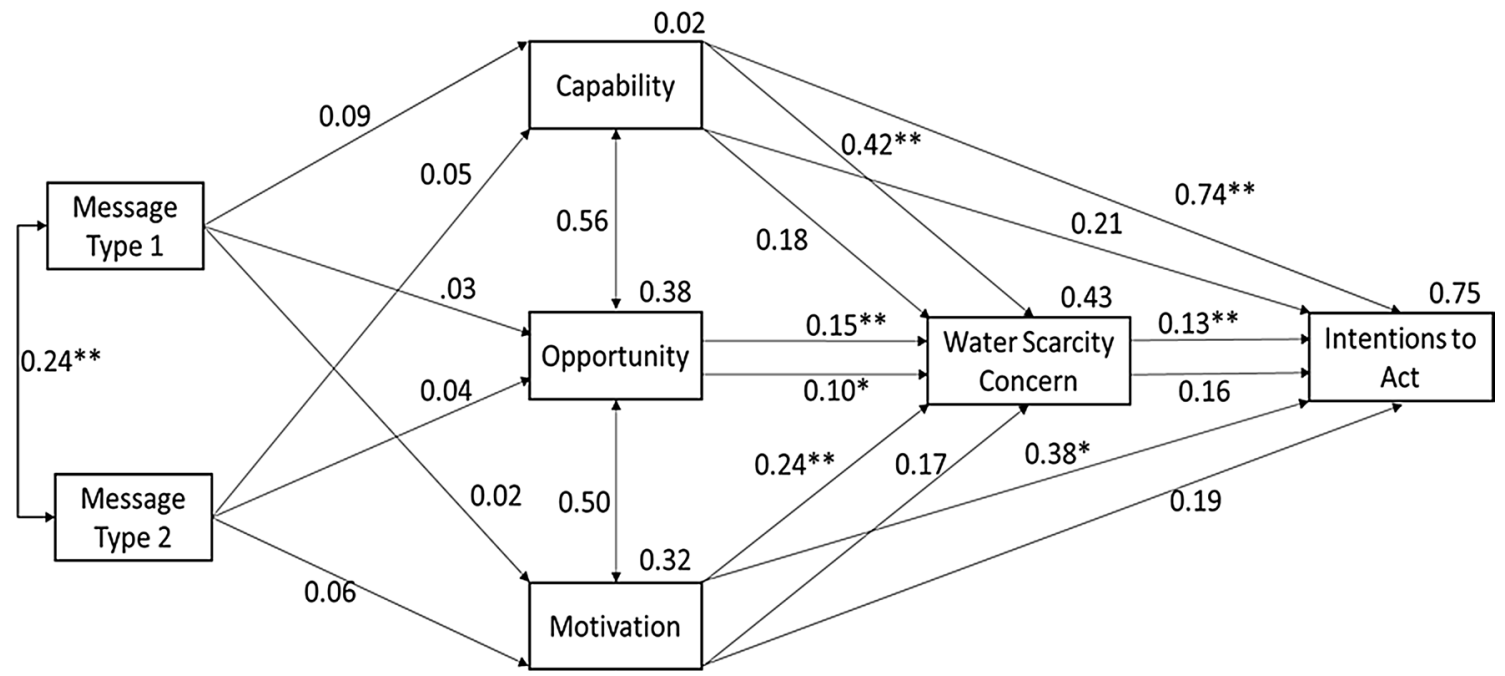

Fig. 2 Path model testing the hypothesis that capability, opportunity, and motivation dimensions mediate the effect of water-conservation message types $(1=$ severe water scarcity - water-saving tips/strategies and $2=$ severe water scarcity—no water-saving tips/strategies) and

water scarcity concern and intentions to act. Values on pathways represent standardised weights. Model fit indices: $\chi^{2}(4, N=510)=6.80$, $P=0.15, \quad \mathrm{GFI}=0.99, \quad \mathrm{CFI}=1.00, \quad \mathrm{RMSEA}=0.04, \quad \mathrm{SRMR}=0.02$. ${ }^{*} p<0.05, * * p<0.01$ 
greater levels of water scarcity concern. Providing explicit information about how to conserve water and avoid wastage increased water scarcity concern and intentions to act in many participants compared to household members who received a message containing no water-saving tips/strategies. In examining the overall variance, the model explained $43 \%$ of the variance in water scarcity concern. The indirect effect of the message types by COM-B interactions was significant for water scarcity concern responses $\left(\beta_{\text {indirect }}=0.19\right.$, $S E=0.07, p<0.01)$.

Participants' perceived capability increased when provided with specific message about how to conserve water. This was associated with higher psychological and physical skills which in turn increased participants' intentions to act (Fig. 1). Results confirmed increased capability $(0.74, p<0.01)$ and motivation $(0.38, p<0.01)$ to be correlated with greater water-conservation intentions when provided with a specific, pragmatic message about how to reduce water consumption. Opportunity also mediated the impact of message type on intentions to act but weakly $(0.13, p<0.01)$. In examining the overall variance, the model explained $75 \%$ of the variance in intentions to act. The indirect effect of the message types by COM-B interactions was significant for intentions to act responses $\left(\beta_{\text {indirect }}=0.15, S E=0.05, p<0.01\right)$.

\section{Discussion}

The COM-B dimensions significantly mediated the effect of each conservation message type on water scarcity concern and intentions to act. In this experimental study, it emerged that households need to be given specific conservation strategies of what to do and how to change otherwise they are less likely to have concern for water scarcity or intent to act. Households that received the no water-saving tips/strategies message showed relatively moderate water scarcity concern but less intention to take water-conservation actions than households that received the water-saving tips/strategies message. The findings of this research showed that providing relevant waterconservation strategies built on causal mechanisms of behaviour influenced conservation behaviour. Studies show that knowledge-based interventions increase residential conservation behaviour such as recycling (Bohner and Dickel 2011; Schultz 2002). Thus, pursuing and promoting water conservation and water saving tips should be knowable and practicable to householders. Our results further showed that care for water conservation increased after individuals received the relevant conservation strategy information. This is in line with other research which shows that personal normative beliefs have a positive effect on water conservation (Corral-Verdugo and Frías-Armenta 2006). Education, persuasion and conservation programs also motivate households environmental and social behaviours (Maas et al. 2017; Corral-Verdugo and
Frías-Armenta 2006) which in turn change the attitudes and behaviours of residential consumers (Landon et al. 2016; Russell and Green 2009; Simpson and Stratton 2011; Fielding and Roiko 2014).

Mediation pathways provided behavioural insights about how the COM-B dimensions changed recipients' level of concern about water scarcity and intentions to engage in conservation actions. It enabled us to determine which output variables (water scarcity concern and intentions to act) remained influenced by our water-conservation message, and which dimensions most predicted water scarcity concern, and intentions to act in water-conservation activities. Pathway analysis showed that water-conservation message types were significantly associated with capability, opportunity, and motivation for water-conservation intentions. This showed that a water-conservation message type can help to reduce water scarcity and increase households' intentions to engage in conservation activities when households can understand conservation messages, have available opportunities, and are motivated. In this respect, our results are consistent with earlier studies that have shown the effectiveness of messages for increasing conservation awareness and activities (Simpson and Stratton 2011; Dolnicar et al. 2012).

Our findings further showed a significant effect of households' capability to perceive water scarcity concern and higher intentions to conserve water. High household capability for water scarcity concern and intentions to act determined households' responsiveness to water-conservation messages. Household members reported more water scarcity concern and greater intentions to act after receiving specific water-conservation messages. The mediating effects of capability on water scarcity concern and intentions to act means that household capability manifests higher levels of water scarcity concern and intentions to act in conserving water. Households that received specific conservation messages become well informed and tuned-into water-conservation actions. This encourages households to acknowledge or receive constructive information about how to decrease their water consumption. Households that received specific conservation strategies as part of their message were more comfortable with taking action to conserve water. They also felt it was important to be alerted to fixing and repairing minor leakages compared to households that did not receive the specific conservation strategy message. Thus, if households are aware of issues related to water shortages and can find conservation strategies, they are more likely to engage in waterconservation actions and exhibit a reduced tendency to waste water. Intensifying water-conservation programs and campaigns (Strang 2001; Letcher et al. 2002) targeted at individuals and communities and offering detailed and holistic views of diminishing water resources may make individuals capable of adopting conservation measures.

Conservation messages can influence households' capability if they are tailored to target the factors underlying this behaviour 
dimension. Household members exhibiting high capability may pay attention to water-conservation messages if those messages are understood and contain relevant conservation strategies. Household capability intensified after they received watersaving tips/strategies message type and likewise, resulted in increased water scarcity concern and intentions to engage in conservation actions, likely because participants respond to communications that are within their domain and coherent with their preferences and prevailing concepts (Sarabia-Sánchez et al. 2014). Overall, increase in water scarcity concern and intentions for water-conservation behaviour was higher when the water-saving tips/strategies communication message given was within the households' capability. Households' higher water scarcity concern and intentions to engage in water-conservation behaviour may be occurring because water crises have been a risk for a prolonged period and many households may have once experienced severe droughts and listened to debates for and against water wastage (Fielding and Roiko 2014).

Opportunity explained significant variation in household water scarcity concern and intentions to act in conservation behaviour in households receiving either conservation message. This is consistent with other research which has shown that communicating water policies (e.g. water governance and retrofitting programs) involving water metering, billing, network repair, and non-pricing strategies (Kenney et al. 2008) impacts water-conservation behaviour. This suggests that households having the opportunity to receive conservation messages are more likely to decrease their volume of water consumption or demand and have a prominent role to play in water management and pro-environmental behaviours. Although households assenting to messages about social opportunity (e.g. social cues, cultural norms, interpersonal influences, and values) are less likely to engage in water-conservation activities (Jorgensen et al. 2009; Graymore and Wallis 2010), those consenting to messages about physical opportunity such as water restrictions, pricing scheme, and locations (Kenney et al. 2008) are more likely to conserve water.

Opportunity not only mediated significantly the effect of message content on households' observed water scarcity concern and intentions to act in conserving water, but, likewise, compelled household tendency to receive or deny water-conservation messages. A significant part of the opportunity dimension on water-conservation messages is water restrictions, providing discounts, rebates, lower rates and free materials or labour for installing water-efficient devices. When households are provided with financial incentives on retrofit programs, there is a high tendency for water reductions (Berry 1984; Inman and Jeffrey 2006). Countries such as Australia, the United States, and the United Kingdom have used financial incentives or retrofit programs that installed new and replaced old appliances such as toilet dams, faucet aerators, and low-flow shower-heads and have achieved remarkable water reductions (Hoque 2014; Richter
2014). In contrast, spending money on water-efficient appliances, high tariffs, and thrifty policies on financial incentive programs may discourage conservation investments and household's participation in conservation activities.

The pathway results for motivation responses showed that support was moderate on water scarcity concern when households were provided with the severe water scarcity and water-saving tips/strategies message. However, augmenting conservation messages with messages about incentives for good conservation behaviour yielded high intentions to act. Households that received information about strategies and how to use them in tackling water crises were prompted to use certified water-efficient appliances and agreed to reduce their water consumption. Specific messages on conservation strategies influence households' cognitive, affective, and behavioural responses to water-conservation behaviour, perceived water scarcity concern, and intentions to act.

One plausible explanation for this finding is that messages about conservation strategies encouraged households to activate and voluntarily recognise their involvement in waterconservation actions and the benefits of these actions to the environment. Positive attitudes, emotions, and reactions to water crises play a significant role in conservation-related issues when households show concern or intent to act, and support for water-conservation regulations (Renwick and Archibald 1998; Lam 2006; Kenney et al. 2008; Bohner and Dickel 2011). It is worthwhile noting that households may do well to engage with water-conservation behaviour when given motivational messages and consider that information as proposing something tangible over and beyond what they perceive. Another prospect is that motivated households are concerned about environmental issues and they try to do all it takes to contest the negative perceptions of pro-environmental behaviours. Messages framed to be pro-conservation can help to reduce domestic water consumption when information underlying conservation activities is linked to the COM-B system (Michie et al. 2011). Individuals will respond better to conservation message contents when they are capable, have the opportunity, and are motivated to engage in pro-environmental behaviour (Vining and Ebreo 1992; Michie et al. 2011). These results give further support for use of the Behaviour Change Wheel model in the field of water-conservation communication.

\section{Conclusions}

As water security has become important in ensuring sustainable local water sources, providing specific water-conservation messages may be important for behavioural change. Conservation messages may be improved by understanding the psycho-social mechanisms of behaviour change. In this study, we have shown that COM-B dimensions mediate the effects of water-conservation messages on water scarcity concern

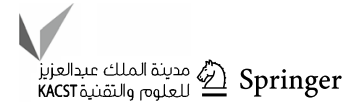


and intentions to act. Conservation messages related to the COM-B dimensions all have a role to play in determining household water-conservation behaviour. The results confirm that providing messages that are specific to the COM-B characteristics about water-conservation strategies can improve households' involvement in and commitment to water-conservation behaviour. The present investigation affirms that for a conservation message to be successful it must move people through changing their behavioural conditions towards maintaining resources at their disposal. The results indicated that specific conservation strategies made available to households had a stronger impact on conservation behaviour when messages appeal to the behavioural change conditions. For example, in localities where water-efficient labelling schemes are in operation, evidence of strenuous message and education programs directing households to their usage and installation are worthwhile (Petty and Cacioppo 1986; Makki et al. 2015). Water- conservation communication efforts do not function in a void and the importance of policy-makers and government water agencies can likewise alter the conversation around water scarcity concern and intentions to act. The COM-B behaviour information can improve water-conservation activities by linking existing strategies to support waterconservation behaviour conditions to reduce vulnerability to environmental risks-including water crises. The COM-B dimensions not only increase behavioural propensity and resilience but enable individuals and households to promote and sustain behavioural and attitudinal change towards proenvironmental behaviour. Specific information is important to inform proper policy responses at the household levels but messages that build on the COM-B dimensions are among the most likely to change conservation behaviour. Future research can identify perceived barriers to and drivers of effective communication that can boost dissemination of information and diffuse resistance to water scarcity concern and intentions to act in decreasing water consumption. It could also explore influences of water-conservation messages among different supply conditions (e.g. reticulated water supply versus nonreticulated water supply) and different climatic regions (e.g. arid versus tropical locations).

Acknowledgements A scholarship from the University of New England for IA is gratefully acknowledged.

\section{Compliance with ethical standards}

Conflict of interest The authors declare that they have no conflict of interest.

Open Access This article is distributed under the terms of the Creative Commons Attribution 4.0 International License (http://creativeco mmons.org/licenses/by/4.0/), which permits unrestricted use, distribution, and reproduction in any medium, provided you give appropriate credit to the original author(s) and the source, provide a link to the Creative Commons license, and indicate if changes were made.

\section{Appendix 1}

See Table 3.

Table 3 Items comprising the water scarcity concern and intentions to act scales

\begin{tabular}{|c|c|}
\hline Scale & Items \\
\hline $\begin{array}{l}\text { Water scarcity } \\
\text { concern }\end{array}$ & $\begin{array}{l}\text { Front-loading washing machine } \\
\text { Water-efficient dishwashers } \\
\text { Water-efficient taps } \\
\text { Tap aerators } \\
\text { Low dual-flush toilet } \\
\text { Low-volume showerhead } \\
\text { Baths and indoor spa } \\
\text { Automatic electronic reticulation system } \\
\text { Sprinklers (drippers/pop-ups) } \\
\text { Hand held hose for garden } \\
\text { Watering can for garden } \\
\text { Hot water insulation } \\
\text { Water collection system for sink/washing } \\
\text { machine/shower } \\
\text { Not automated reticulation system } \\
\text { I install and use pool cover }\end{array}$ \\
\hline Intentions to act & $\begin{array}{l}\text { I strictly adhere to water restrictions } \\
\text { I rarely water my garden } \\
\text { I reduce lawn area } \\
\text { I do not wash my car with water } \\
\text { I use drought-resistant grass } \\
\text { I connect rain tank to garden } \\
\text { I use a watering can, not hose } \\
\text { I install and use efficient irrigation } \\
\text { I wash car less often } \\
\text { I collect water from shower/sink/bath for use } \\
\text { elsewhere } \\
\text { I recycle grey water from the washing machine } \\
\text { for garden } \\
\text { I recycle grey water from the shower for garden } \\
\text { I have a drought-tolerant plants/low water con- } \\
\text { sumption garden } \\
\text { I mulch garden regularly } \\
\text { I group plants with similar needs } \\
\text { I collect water when it rains (not in a rainwater } \\
\text { tank) } \\
\text { I water garden according to conditions } \\
\text { I irrigate in the morning or evening } \\
\text { I have a rain water tank } \\
\text { I allow my lawn to go brown if there is insuf- } \\
\text { ficient rain } \\
\text { Stopping what I am doing to turn off a dripping } \\
\text { tap } \\
\text { Conserving water is my responsibility } \\
\text { Checking for regular plumbing leaks }\end{array}$ \\
\hline
\end{tabular}




\section{Appendix 2}

See Table 4.

Table 4 Items comprising the COM-B scales

\begin{tabular}{|c|c|c|}
\hline Dimension & Items & Sub-dimensions \\
\hline Capability & $\begin{array}{l}\text { Looking out for news and facts on water shortages and crises areas } \\
\text { Knowing the effective methods of watering garden to save water } \\
\text { Understanding the negative impacts of water scarcity on sustainable livelihood } \\
\text { Providing information about water conservation to householders } \\
\text { Taking feedback about the level of water consumption seriously to check my water usage } \\
\text { Prioritising ecological issues such as water scarcity and pollution } \\
\text { Understanding the impacts of water shortages and conservation processes } \\
\text { Communicating the severity of water scarcity to neighbours/families } \\
\text { Learning about water crises and their consequences on the environment } \\
\text { Harvesting rainwater for the garden } \\
\text { Using a bucket instead of a hose to water the garden } \\
\text { Using water-efficient appliances in my house } \\
\text { Checking and fixing leaking water-efficient plumbing fixtures } \\
\text { Planting hardy plants/drought-resistant xeriscape gardening } \\
\text { Having power spray attached to a hose } \\
\text { Owning water-efficient electrical appliances } \\
\text { Minimising the flushing of toilets and bath times }\end{array}$ & $\begin{array}{l}\text { Psychological capability } \\
\text { Psychological capability } \\
\text { Psychological capability } \\
\text { Psychological capability } \\
\text { Psychological capability } \\
\text { Psychological capability } \\
\text { Psychological capability } \\
\text { Psychological capability } \\
\text { Psychological capability } \\
\text { Physical capability } \\
\text { Physical capability } \\
\text { Physical capability } \\
\text { Physical capability } \\
\text { Physical capability } \\
\text { Physical capability } \\
\text { Physical capability } \\
\text { Physical capability }\end{array}$ \\
\hline Opportunity & $\begin{array}{l}\text { People conserve water because of their cultural beliefs } \\
\text { Social pressure is a key factor for water conservation } \\
\text { I think financial incentives or rebates are likely to promote water-conservation measures } \\
\text { I strictly adhere to water restrictions } \\
\text { It is advisable/mandatory to use quality water-efficient appliances }\end{array}$ & $\begin{array}{l}\text { Social opportunity } \\
\text { Social opportunity } \\
\text { Physical opportunity } \\
\text { Physical opportunity } \\
\text { Physical opportunity }\end{array}$ \\
\hline Motivation & $\begin{array}{l}\text { Informing myself about flow regulators } \\
\text { Supporting environmental pressure groups to protect the natural resources } \\
\text { Informing myself about certified water-efficient appliances } \\
\text { Feeling upset when I see someone using water to wash the footpath/sidewalk or driveway } \\
\text { Feeling indignant at the lack of awareness of some people regarding water conservation } \\
\text { Feeling frustrated when I see a toilet/tap running without anyone doing anything about it } \\
\text { Feeling guilty when I leave a tap running } \\
\text { Feeling good when I can save water } \\
\text { Feeling happy to see someone who is trying to save water } \\
\text { Feeling upset by the waste of water in public places } \\
\text { Rinsing vegetables under running water } \\
\text { Showering for less than } 3 \text { min } \\
\text { Wanting to complain when I see someone wasting water } \\
\text { Washing vegetables in a bucket or sink instead of running water } \\
\text { Stopping what I am doing to turn off a dripping tap } \\
\text { Conserving water is my responsibility } \\
\text { Checking for regular plumbing leaks }\end{array}$ & $\begin{array}{l}\text { Reflective motivation } \\
\text { Reflective motivation } \\
\text { Reflective motivation } \\
\text { Reflective motivation } \\
\text { Reflective motivation } \\
\text { Reflective motivation } \\
\text { Reflective motivation } \\
\text { Reflective motivation } \\
\text { Reflective motivation } \\
\text { Reflective motivation } \\
\text { Automatic motivation } \\
\text { Automatic motivation } \\
\text { Automatic motivation } \\
\text { Automatic motivation } \\
\text { Automatic motivation } \\
\text { Automatic motivation } \\
\text { Automatic motivation }\end{array}$ \\
\hline
\end{tabular}




\section{References}

Addo IB, Thoms MC, Parsons M (2018) Household water use and conservation behavior: a meta-analysis. Water Resour Res 54:83818400. https://doi.org/10.1029/2018WR023306

Alexander KE, Brijnath B, Mazza D (2014) Barriers and enablers to delivery of the Healthy Kids Check: an analysis informed by the Theoretical Domains Framework and COM-B model. Implement Sci 9:60

Arbuckle JL (2006) SPSS AMOS version 24.0 computer software. IBM, Chicago

Barker F, Atkins L, de Lusignan S (2016) Applying the COM-B behaviour model and behaviour change wheel to develop an intervention to improve hearing-aid use in adult auditory rehabilitation. Int $\mathrm{J}$ Audiol 55(sup3):S90-S98

Bemelmans-Videc ML, Rist RC, Vedung EO (eds) (2011) Carrots, sticks, and sermons: Policy instruments and their evaluation, vol 1. Transaction, New Brunswick

Berry L (1984) The role of financial incentives in utility-sponsored residential conservation programs: a review of customer surveys. Eval Program Plan 7(2):131-141

Bohner G, Dickel N (2011) Attitudes and attitude change. Annu Rev Psychol 62(4):391-417

Bryan A, Fisher J, Fisher W, Murray D (2000) Understanding condom use among heroin addicts in methadone maintenance using the information-motivation-behavioral skills model. Subst Use Misuse 35:451-471

Corral-Verdugo V, Frías-Armenta M (2006) Personal normative beliefs, antisocial behavior, and residential water conservation. Environ Behav 38(3):406-421. https://doi.org/10.1177/001391650528227 2

Dolnicar S, Hurlimann A, Grün B (2012) Water conservation behaviour in Australia. J Environ Manag 105:44-52

Farley KA, Bremer LL (2017) "Water is life": local perceptions of páramo grasslands and land management strategies associated with payment for ecosystem services. Ann Am Assoc Geogr 107(2):371-381

Fielding KS, Roiko AH (2014) Providing information promotes greater public support for potable recycled water. Water Res 61(2):86-96

Fielding KS, Russell S, Spinks A, Mankad A (2012) Determinants of household water conservation: the role of demographic, infrastructure, behaviour, and psychosocial variables. Water Resour Res 48(10):1-12. https://doi.org/10.1029/2012WR012398

Fielding KS, Spinks A, Russell S, McCrea R, Stewart R, Gardner J (2013) An experimental test of voluntary strategies to promote urban water demand management. J Environ Manag 114:343-351

Fisher JD, Fisher WA (1996) The Information-Motivation-Behavioral skills model of AIDS risk behavior change: Empirical support and application. In: Oskamp S, Thompson S (eds) Understanding and preventing HIV risk behavior: safer sex and drug use. Sage, Thousand Oaks

Fisher JD, Fisher WA, Sunyna W, Thomas M (1994) Empirical tests of an information-motivation-behavioral skills model of AIDSpreventive behavior with gay men and heterosexual university students. Health Psychol 13:238-250

Gober P, Kirkwood CW, Balling RC, Ellis AW, Deitrick S (2010) Water planning under climatic uncertainty in Phoenix: why we need a new paradigm? Ann Am Assoc Geogr 100(2):356-372

Graymore ML, Wallis AM (2010) Water savings or water efficiency? Water-use attitudes and behaviour in rural and regional areas. Int J Sustain Dev World Ecol 17(1):84-93

Hine DW, Reser JP, Phillips WJ, Cooksey R, Marks AD, Nunn P, Glendon AI (2013) Identifying climate change interpretive communities in a large Australian sample. J Environ Psychol 36:229-239
Hoekstra AY, Chapagain AK (2007) Water footprints of nations: water use by people as a function of their consumption pattern. Water Resour Manag 21(1):35-48

Hoque SF (2014) Water conservation in urban households: Role of prices, practices and technologies. IWA Publishing, London

Inman D, Jeffrey P (2006) A review of residential water conservation tool performance and influences on implementation effectiveness. Urban Water J 3(3):127-143

Jackson C, Eliasson L, Barber N, Weinman J (2014) Applying COM-B to medication adherence: a suggested framework for research and interventions. Eur Health Psychol 16(1):7-17

Jorgensen B, Graymore M, O'Toole K (2009) Household water use behavior: an integrated model. J Environ Manag 91(1):227-236

Kenney DS, Goemans C, Klein R, Lowrey J, Reidy K (2008) Residential water demand management: lessons from Aurora, Colorado. J Am Water Resour Assoc 44(1):192-207

Lam SP (2006) Predicting intention to save water: theory of planned behaviour, response efficacy, vulnerability, and perceived efficiency of alternative solutions. J Appl Soc Psychol 36(11):2803-2824

Landon AC, Kyle GT, Kaiser RA (2016) Predicting compliance with an information-based residential outdoor water conservation program. J Hydrol 536:26-36

Letcher RA, Jakeman AJ, Calfas M, Linforth S, Baginska B, Lawrence I (2002) A comparison of catchment water quality models and direct estimation techniques. Environ Model Softw 17(1):77-85

Maas A, Goemans C, Manning D, Kroll S, Arabi M, RodriguezMcGoffin M (2017) Evaluating the effect of conservation motivations on residential water demand. J Environ Manag 196:394-401

Makki AA, Stewart RA, Beal CD, Panuwatwanich K (2015) Novel bottom-up urban water demand forecasting model: revealing the determinants, drivers and predictors of residential indoor end-use consumption. Resour Conserv Recycl 95:15-37

McGranahan G (2002) Demand-side water strategies and the urban poor. IIED, London

McKenzie-Mohr D (2008) Fostering sustainable behavior: beyond brochures. Int J Sustain Commun 3:108-118

McKenzie-Mohr D, Nemiroff LS, Beers L, Desmarais S (1995) Determinants of responsible environmental behavior. J Soc Issues 51(4):139-156

McLeod LJ, Hine DW, Please PM, Driver AB (2015) Applying behavioral theories to invasive animal management: towards an integrated framework. J Environ Manag 161:63-71

Michie S, van Stralen MM, West R (2011) The behaviour change wheel: a new method for characterising and designing behaviour change interventions. Implement Sci 6(1):1-12

Moore JE, Mascarenhas A, Marquez C, Almaawiy U, Chan WH, D’Souza J, Straus SE (2014) Mapping barriers and intervention activities to behaviour change theory for Mobilization of Vulnerable Elders in Ontario (MOVE ON), a multi-site implementation intervention in acute care hospitals. Implement Sci 9(1):160. https ://doi.org/10.1186/s13012-014-0160-6

Petty RE, Cacioppo JT (1986) Communication and persuasion: Central and peripheral routes to attitude change. Springer, New York

Postel SL, Daily GC, Ehrlich PR (1996) Human appropriation of renewable fresh water. Science 271:785-788

Renwick ME, Archibald SO (1998) Demand side management policies for residential water use: who bears the conservation burden? Land Econ 74(3):343-359

Richter B (2014) Chasing water: a guide for moving from scarcity to sustainability. Island Press, Washington

Russell S, Green M (2009) An audit of social science questions emerging from south-east Queensland Urban Water Security Research Alliance Projects. CSIRO Water for a Healthy Country National Research Flagship. CSIRO, Canberra 
Sarabia-Sánchez FJ, Rodríguez-Sánchez C, Hyder A (2014) The role of personal involvement, credibility and efficacy of conduct in reported water conservation behaviour. J Environ Psychol 38:206-216

Schultz PW (1999) Changing behavior with normative feedback interventions: a field experiment of curb side recycling. Basic Appl Soc Psychol 21:25-36

Schultz PW (2002) Knowledge, information, and household recycling: examining the knowledge-deficit model of behavior change. In: Dietz T, Stern P (eds) Education, information, and voluntary measures in environmental protection. National Academy of Sciences, Washington, DC, pp 67-82

Seyranian V, Sinatra GM, Polikoff MS (2015) Comparing communication strategies for reducing residential water consumption. J Environ Psychol 41:81-90

Simpson J, Stratton H (2011) Talking about water: words and images that enhance understanding. Waterlines Report Series No 49, National Water Commission, Canberra. http://www.nwc.gov.au/ data/assets/pdffile/0020/10928/49talkingaboutwater.pdf. Accessed 16 Nov 2017

Stiles G (1996) Demand-side management, conservation, and efficiency in the use of Africa's water resources. In: Rached E, Rathgeber E,
Brooks D (eds) Water management in Africa and the Middle East: challenges and opportunities. IDRC Books, Ottawa

Strang V (2001) Evaluating water: cultural beliefs and values about water quality, use and conservation. Oxford

Thurstone LL (1947) Multiple-factor analysis. University of Chicago Press, Chicago

Vining J, Ebreo A (1992) Predicting recycling behavior from global and specific environmental attitudes and changes in recycling opportunities. J Appl Soc Psychol 22(20):1580-1607

Wilbanks TJ, Kates RW (2010) Beyond adapting to climate change: embedding adaptation in responses to multiple threats and stresses. Ann Am Assoc Geogr 100(4):719-728

World Economic Forum (2014) The global competitiveness report 2013-2014. World Economic Forum, Geneva

Publisher's Note Springer Nature remains neutral with regard to jurisdictional claims in published maps and institutional affiliations. 